\title{
Effects of deflectors in liquid-liquid pintle injector with various momentum ratio
}

\author{
Ingyu Lee ${ }^{1}$, Gijeong Jeong ${ }^{2}$, Youngbin Yoon*1 \\ ${ }^{1}$ Department of Aerospace Engineering, Seoul National University, Seoul, Republic of Korea \\ ${ }^{2}$ School of Mechanical Engineering, Chungbuk National University, Cheongju, \\ Republic of Korea
}

\begin{abstract}
Since the APOLLO project was terminated in 1970's, lunar exploration was not been carried out until 2010's. In order to achieve the landing on the surface, pintle injector is required. Due to it's limitation on configuration, however, an engine with the injector has to resolve the heat problem on pintle tip and injector. In this study, effect of the deflector on annular jet was investigated as a solution for the defect. Four configurations were designed to investigate the characteristics of the injector and various momentum ratio conditions were applied to experiments. Backlight image processing method was used to understand the spray characteristics though high speed camera. When the deflector angle becomes smaller, spray angle variation before an after impingement becomes smaller, which means that lower angled of deflect shows more stabilized. In the low mass flow rate, the liquid film does not breakup well for all cases. And it was found that radial velocity related to higher atomization performance increases as the height $(\mathrm{H})$ becomes smaller. An directional momentum ratio rather than momentum ratio for each propellant was suggested. Spray angle prediction with conventional momentum ratio underestimated the spray angle, but with directional momentum ratio, spray angle was predicted well.
\end{abstract}

\section{Keywords}

Liquid-Liquid Pintle Injector, Spray angle, Deflector

\section{Introduction}

Since the APOLLO project was terminated in 1970's, lunar exploration was not been carried out until 2010's. With NASA's announcement of the ARTEMIS project, interest in lunar landing is increasing again[1]. In order to achieve the landing on the surface, pintle injector is required. Pintle injector is well known for it's benefits such as cost saving, weight, stable combustion and high performance[2]. Due to it's limitation on configuration, however, an engine with the injector has to resolve the heat problem on pintle tip and injector[3]. Additional cooling channel on pintle, which is representative method, could reduce the problems[4]. Lee et al investigated effectiveness of the cooling channel and found that pintle tip can be cooled down with the channel[4]. For a small scale engine, however, small injector is required and it is difficult to design the cooling passage also. Therefore, another method, called deflector, to reduce the problem is suggested[3]. Brunno B. Vasques et al, were investigated way to prevent melting down the pintle tip. They performed cold and hot test with deflector and the deflector helps firing time extended [3]. Even though firing test was performed well, characteristics on cold flow of pintle with deflector has been insufficient compared to the other method.

In this study, effect of deflector on pintle injector was investigated with image processing method under $50 \%, 100 \%, 150 \%$ mass flow rate condition. Total Momentum Ratio(TMR, J) was used as main variables because the it is difficult to represent the actual conditions for mass flow rate and, the TMR is used as main parameter generally. 


\section{Material and Methods}

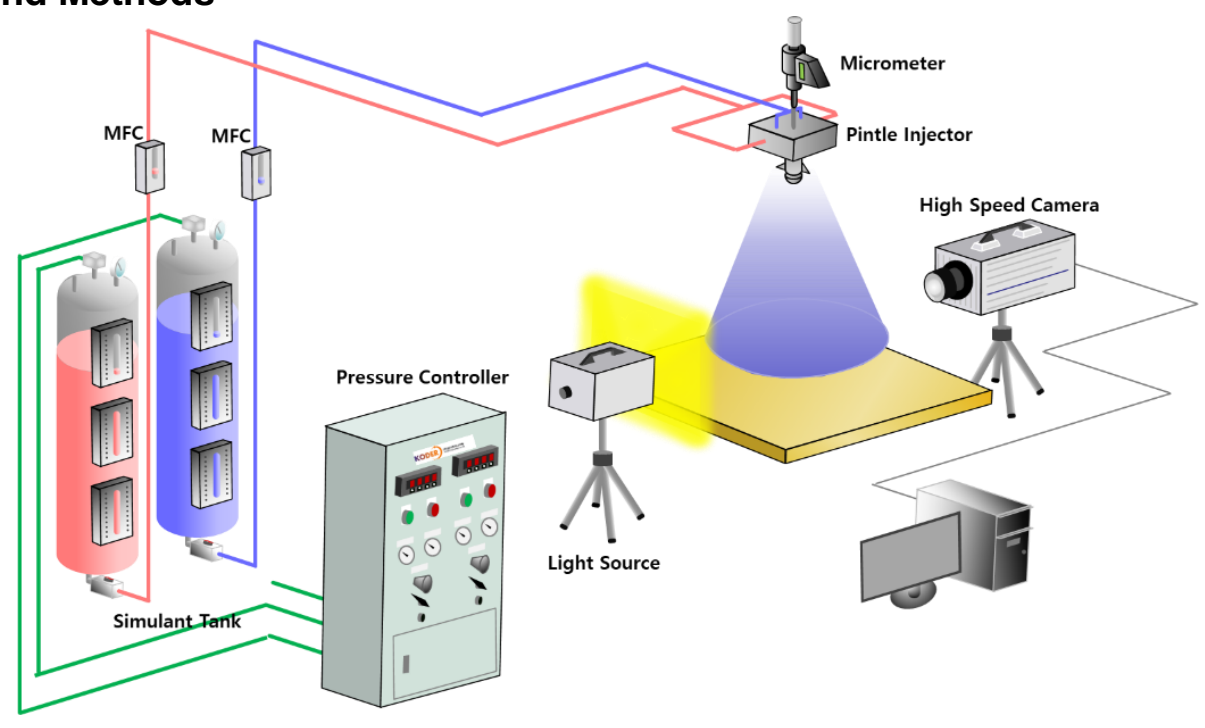

Figure 1. Schematics of Liquid-Liquid Pintle Injector Test Facility

The experimental setup of this study is shown in Figure 1. Water was used as propellant simulant for convenience on this study. In order to supply the fluid on pintle injector, simulant water was filled and pressurized in the tank. A supply line for the water, which is used as simulant, was equipped with mass flow controller to control and monitor the mass flow rate and O/F ratio in constant. A continuous light source(HVC-SL) and high speed camera(High Speed Star 8) was installed to capture the backlight images of external flow. The frame rate $(6,000 \mathrm{fps})$ and exposure time $(1 / 20,000 \mathrm{sec})$ of the images were set to detect the instantaneous characteristics.

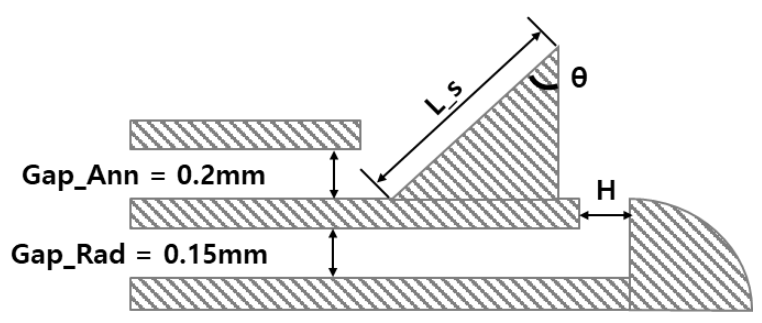

Figure 2. Schematics of pintle injector
Table 1. Test Conditions and Injector Dimension

\begin{tabular}{|c|c|c|}
\hline \multicolumn{3}{|c|}{ Test Conditions } \\
\hline Propellant & $\begin{array}{c}\text { RP-1 } \\
\text { (Annular flow) }\end{array}$ & $\begin{array}{c}\text { LOX } \\
\text { (Radial flow) }\end{array}$ \\
\hline Throttling level [\%] & \multicolumn{2}{|c|}{50 to 150} \\
\hline Pintle diameter $\left[D_{p}, m m\right]$ & \multicolumn{2}{|c|}{10} \\
\hline Skip length $\left[\mathbf{L}_{s}, m m\right]$ & \multicolumn{2}{|c|}{10} \\
\hline Impinging Angle $[\theta, \mathrm{deg}]$ & \multicolumn{2}{|c|}{$90.0 / 67.5 / 45.0 / 22.5$} \\
\hline Height $[\mathrm{H}, \boldsymbol{m m}]$ & \multicolumn{2}{|c|}{$0.4 / 0.7 / 1.0 / 1.3$} \\
\hline
\end{tabular}

Figure 2. shows the geometry of the pintle injector for this paper. Compared to discrete type pintle injector, the atomization performance of continuous type pintle injector shows better in previous works. Therefore, the continuous type design was applied in this study. And micrometer, as shown in figure 1, was installed in top of the injector to modulate the opening height of the radial injection area.

Generally, pintle injector is well known for it's advantages such as higher performance and stable combustion. However, pintle tip goes melt due to It' geometrical characteristics. So, an deflector, which forced the annular flow angle larger, was installed on pintle post and it is expected to make spray stabilized and reduce the recirculation zone. In order to investigate 
the effect of deflector angle, 90.0/67.5/45.0/22.5 deg angle of injector was tested with various throttling level ( $50 \%$ to $150 \%)$.

\section{Results and Discussion}

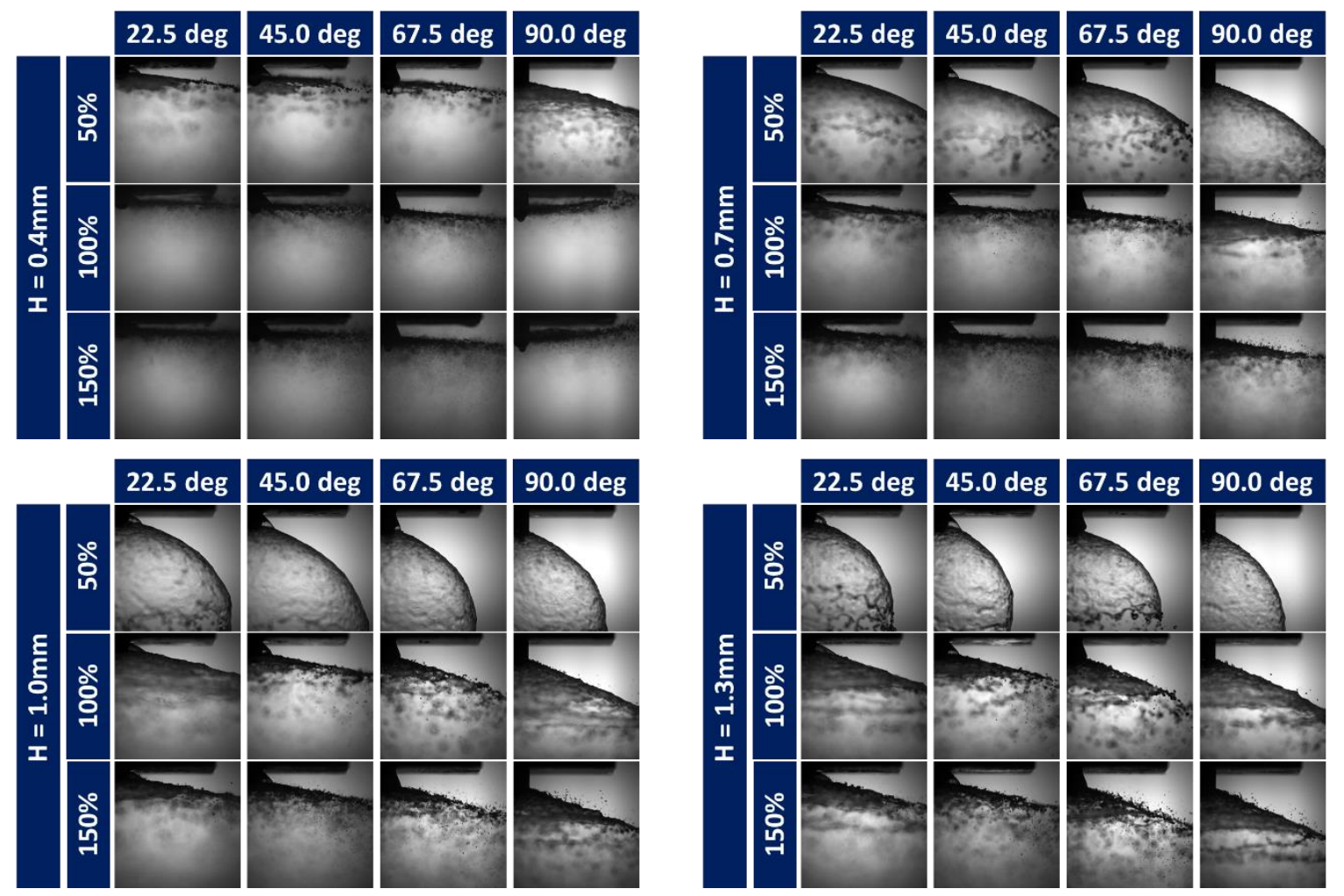

Figure 3. Spray Patterns with various angle, mass flow rate and opening height

Figure 3 is the spray patterns of all conditions in this study. The case for the opening height $=$ $0.4 \mathrm{~mm}$ shows different trend from the other cases. Friction force induced by radial injection velocity between liquid film and ambient air of these cases is enough to break the liquid film. However, the momentum for each direction is not enough to achieve atomization for the other cases under low mass flow rate region(50\%). And cases for over $50 \%$ mass flow rate, $0.7 \mathrm{~mm}$ of opening height and below $67.5 \mathrm{deg}$ of deflector, impinging force and shear force of simulant is enough to atomization.

To qualify the spray angle after impingement of both simulants, at least 5,000 images were averaged for each case. An edge of the liquid film was defined as maximum intensity gradient point from injector plate to bottom.

In order to investigate the overall spray characteristics, directional total momentum ratio(J) was defined as in the equation below :

$$
\begin{aligned}
& V_{\text {oxi }}=\frac{\dot{m}_{\text {oxi }}}{\rho A_{\text {oxi }}}, V_{\text {fuel }}=\frac{\dot{m}_{\text {fuel }}}{\rho A_{\text {fuel }}} \\
& \mathrm{J}=\frac{\sum(\dot{m} V)_{x-\text { dir }}}{\sum(\dot{m} V)_{y-d i r}}=\frac{\left(\rho A_{\text {oxi }} V_{\text {oxi }}\right)_{x-\text { dir }}+\left(\rho A_{\text {fuel }} V_{f u e l}\right)_{x-\text { dir }}}{\left(\rho A_{\text {fuel }} V_{\text {fuel }}\right)_{y-\text { dir }}}=\frac{\left(\rho V_{\text {oxi }}^{2}\right)_{x-\text { dir }}+\left(\rho V_{\text {fuel }}^{2}\right)_{x-\text { dir }}}{\left(\rho V_{\text {fuel }}^{2}\right)_{y-\text { dir }}}
\end{aligned}
$$


where $\rho, \mathrm{A}_{\text {oxi }}, \mathrm{A}_{\text {fuel }}, V_{\text {oxi }}, V_{\text {fuel }}$ are simulant density, oxidizer(radial) injection area, fuel(annular) injection area, oxidizer(radial) injection velocity, and fuel(annular) injection velocity, respectively. The momentum of annular flow can be divided into directional component thanks to the deflector. It is expected that these directional components make spray characteristics of the injector similar to those of shear coaxial injector. Total momentum ratio is related to the opening height $(\mathrm{H})$. The directional total momentum ratio becomes larger as the opening height $(\mathrm{H})$ goes larger at fixed mass flow rate and constant mass flow rate.

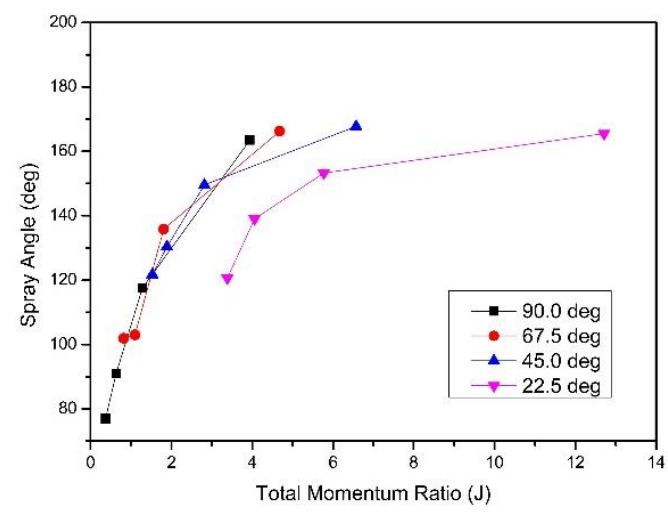

(a) $50 \%$ mass flow rate

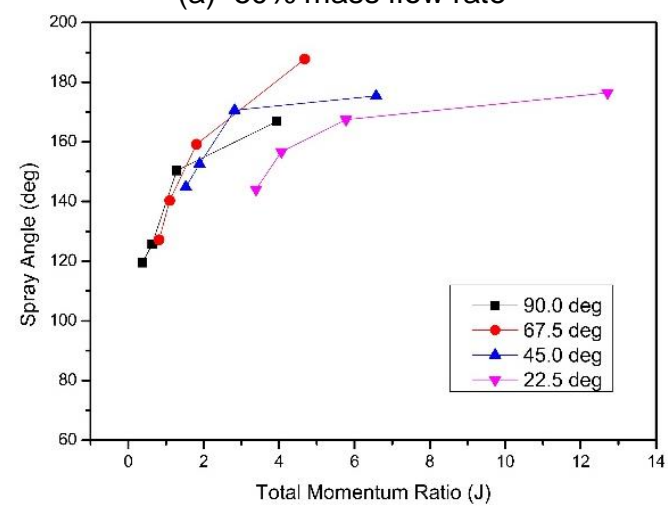

(c) $150 \%$ mass flow rate

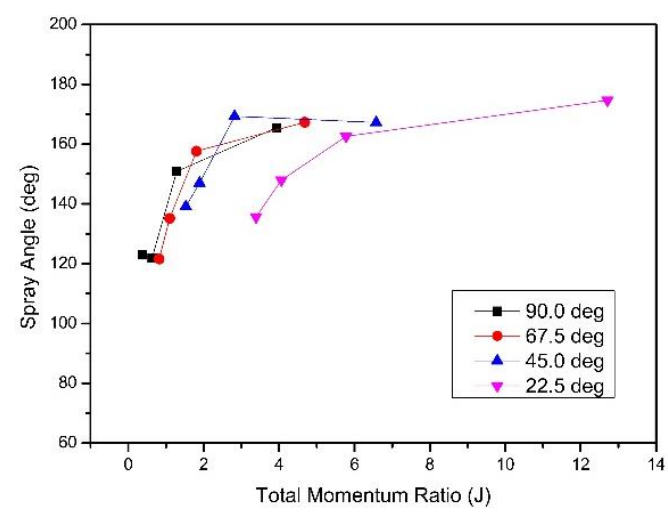

(b) $100 \%$ mass flow rate

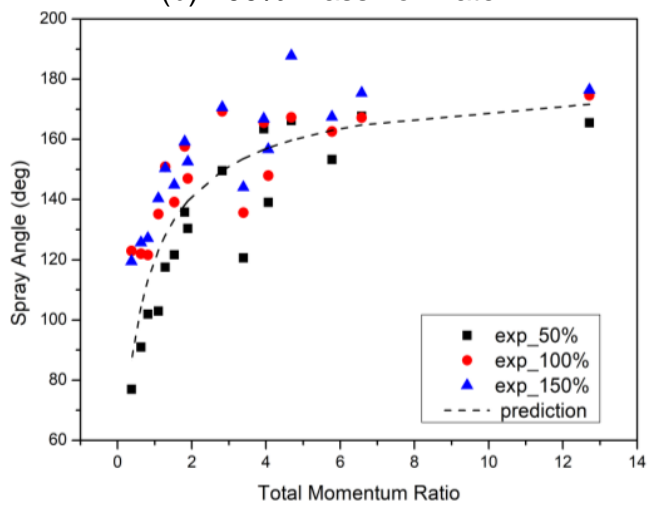

(d) mass flow rate

Figure 4 Spray Angle with various total momentum ratio and mass flow rate

As the directional total momentum ratio become larger, spray angle becomes larger for all mass flow rate and deflector angle conditions. Spray angle variation trend seems same except 22.5 degree case under low mass flow rate. It's because momentum of annular flow was reduced when the flow passes over the deflector for these cases. However, spray angle seems stable over directional total momentum ratio above 5 regardless of the mass flow rate and deflector angle. From the result, it can be confirmed that spray angle can be stabilized over certain TMR. Also, spray angle can be predicted well using the directional total momentum ratio(J) as described regardless of deflector angle :

$$
\text { Spray Angle }\left(\theta^{\prime}\right)=2 \cos ^{-1} \frac{1}{1+T M R}
$$

\section{Conclusions}

So far, the spray characteristics of pintle injector with deflector has been investigated. It was found that cases for over $50 \%$ mass flow rate, $0.7 \mathrm{~mm}$ of opening rate and below 67.5 deg of deflector, impinging force and shear force of simulant is enough to atomization. Spray angle prediction with conventional momentum ratio underestimated the spray angle, but with 
directional total momentum ratio, spray angle was predicted well. When the deflector angle increases, directional total momentum ratio is supposed to be increase. So, the spray angle can be stabilized earlier under the same mass flow rate region. Also, it is expected that atomization performance would be improved because the effect of shear force increases. In the future, it will be investigated that the effect of shear force, induced by deflector, is investigated through SMD measurement.

\section{Acknowledgments}

This work was supported by the National Research Foundation of Korea (NRF) grant funded by the Korea government (MSIP) (2019M1A3A1A02076963), contracted through the Institute of Advanced Aerospace Technology, SNU.

\section{References}

[1] NASA, https://www.nasa.gov/specials/artemis/

[2] Casiano, M. J., Hulka, J. R. and Yang, V., Liquid-Propellant Rocket Engine Throttling: A Comprehensive Review, 2010, Journal of propulsion and power, 26(5), pp. 897 923

[3] Brunno B. Vasques and Oskar J. Haidn, Effect of Pintle Injector Element Geometry on Combustion in a Liquid Oxygen/Liquid Methane Rocket Engine, July. 3.-6. 2017 , 7th European Conference for Aeronautics and Aerospace Science.

[4] Keonwoong Lee, Jeonsoo Nam, Kanmaniraja Radhakrishnan and Jaye Koo, Effect of Internal Flow Guide in Pintle Tip on Pintle Injector Thruster Combustion, 2020, Journal of Korean Society of Aeronutical Space and Science, 48(9), pp. 703-709. 